\title{
Husserl, impure intentionalism, and sensory awareness
}

\author{
Corijn Van Mazijk ${ }^{1}$
}

Published online: 24 January 2018

(C) The Author(s) 2018. This article is an open access publication

\begin{abstract}
Recent philosophy of mind has seen an increase of interest in theories of intentionality in offering a functional account of mental states. The standard intentionalist view holds that mental states can be exhaustively accounted for in terms of their representational contents. An alternative view proposed by Tim Crane, called impure intentionalism, specifies mental states in terms of intentional content, mode, and object. This view is also suggested to hold for states of sensory awareness. This paper primarily develops an alternative to the impure intentionalist account of states of sensory awareness. On the basis of Husserl's phenomenological work, I argue that a focus on intentionality at the level of sensory awareness is phenomenologically implausible. The final part offers an alternative functional account of sensory awareness based on what Husserl called 'immanent association'.
\end{abstract}

Keywords Intentionalism $\cdot$ Representationalism $\cdot$ Phenomenal content $\cdot$ Sensory awareness · Sensations · Husserl · Intentionality · Phenomenology $\cdot$ Qualia

\section{Introduction}

Recent philosophy of mind has seen an increase of interest in theories of intentionality in discussing consciousness. Over the past three decades, intentionalism developed into one of the most promising candidates for offering a viable 'mark of the mental', that is, a unifying theory of consciousness.

The term 'intentionalism' is today used for a variety of different theories, including Byrne (2001, 2009), Crane (1998, 2003, 2009), Marcus (2006), and Stoljar (2007). According to most proponents of intentionalism, the term 'intentionalism' is synonymous with 'representationalism'. Crane, for instance, suggests that 'intentional content is

Corijn Van Mazijk

c.m.a.van.mazijk@rug.nl

1 Faculty of Philosophy, Department of the History of Philosophy, University of Groningen, Oude Boteringestraat 52, 9712GL Groningen, The Netherlands 
representational content' and denies that there is a substantial difference between both terms (Crane 2009, 477). I follow Crane on this point, which means the class of intentionalist theories of mind can likewise be taken to include the representationalist theories of Harman (1990), Dretske (1995), Tye (1995, 2002), Shoemaker (1998, 2000), Bain (2003), Lycan (2001, 2015), Schellenberg (2011), and Bourget (2015), among others.

While differences between various forms of intentionalism are quite substantial, most intentionalists agree on the general thesis that consciousness can be exhaustively described in terms of its representational contents. Put differently, what it is like to enjoy any particular experience can be assessed sufficiently in terms of what that experience represents. Sometimes, this idea is taken to be supported by the so-called 'transparency thesis': the suggestion that introspection would reveal nothing about our experience apart from what is being represented. ${ }^{1}$ I will refer to the theory that consciousness can be assessed sufficiently in terms of what is represented as the 'standard intentionalist view' or 'standard intentionalism'.

This broad interpretation of intentionalism still leaves numerous important questions open. For instance, it leaves it open whether consciousness is determined by or entirely reducible to a function of representing, ${ }^{2}$ whether the representational contents at stake are conceptual or non-conceptual, ${ }^{3}$ and whether they are narrow or wide. ${ }^{4}$ Important as each of these questions may be, they will not be of further concern in this paper.

In Intentionalism from 2009, Crane argues that there is a yet more fundamental distinction to be made within the class of intentionalist theories. According to him, the so-called 'pure intentionalist' view holds that consciousness is 'determined by its representational content' (Crane 2009, 475). This description coincides with the standard intentionalist view I discussed so far, according to which consciousness can be adequately accounted for in terms of what is being represented. This standard view differs, however, from Crane's own theory, which suggests that consciousness is determined 'by its entire intentional nature' (Crane 2009, 475). The entire intentional nature, for Crane, includes not only the representational content, but also the so-called 'intentional mode' and the 'intentional object'. Crane coins this theory impure intentionalism. Impure intentionalism, then, while sharing a general outlook with standard intentionalism, objects to the latter's sole obsession with intentional content. ${ }^{5}$

In a recently published paper, ${ }^{6}$ I juxtaposed Husserl's theory of intentionality from Ideas I (1913) to the standard intentionalist view. In doing this, I defended three main claims. First, I argued that Husserl's theory of intentionality offers resources to argue against standard intentionalism's sole concern with propositional contents. Second, I argued that for Husserl, intentionality is not the trait of the mental. Instead, I claimed that it covers only a region or class of contents, namely those which characterize

\footnotetext{
${ }^{1}$ See Harman (1990), Martin (2002), Tye (2002), and also Pace (2007) for a criticism of the transparency thesis.

2 The first position is usually called 'weak representationalism', endorsed for instance by Dretske (1995). The second view is called strong representationalism, of which Tye (1995) is a proponent. Crane (2009) refers to these positions as 'weak pure intentionalism' and 'strong pure intentionalism' respectively. The nature of this dispute is ontological. As such, it plays no significant role in this paper.

${ }^{3}$ See especially Crane (1992) for an early discussion, McDowell $(1994,1996,2013)$ for an epistemological account, or my own overview of the debate in phenomenological circles (Van Mazijk 2017a).

${ }^{4}$ See for instance Loar (1988).

${ }^{5}$ Crane also objects to its sole concern with propositional content, which I bypass here.

${ }^{6}$ Van Mazijk (2017b).
} 
'consciousness in the pregnant sense' (Husserl 1983, 199). Put differently, in terms of the phenomenology of consciousness, intentionality concerns predominantly the egosubject's practical and theoretical comportment toward things, but it does not necessarily apply to all aspects of consciousness. Third, I claimed that Husserl sees intentionality (as a regional domain within consciousness) as a relation between actprocesses and presented content. As for Crane, then, for Husserl intentional consciousness cannot be adequately addressed exclusively in terms of represented contents; it requires referring to act-processes and their various sub-components as well.

Especially this third claim seems to put Husserl's theory of intentionality in closer proximity to Crane's impure intentionalism than to the standard intentionalist view. After all, both prefer to speak of consciousness in terms of an intentional relation rather than exclusively as what is represented in virtue of that relation. As a matter of fact, Crane's theory relies strongly on the work of Brentano and to a lesser extent also on that of Husserl. Correlatively, Crane explicitly frames impure intentionalism as a phenomenological theory, which could render a comparison to Husserl's work fruitful.

As a kind of follow-up on my previous work, this paper first provides a critical discussion of impure intentionalism and then an alternative to it based on Husserl's phenomenological work. I will not repeat the details of my earlier discussions only to exchange the object of comparison to Crane's impure variant of intentionalism, however. Rather, the second claim I defended previously - that intentionality is not the mark of the mental for Husserl - can be seen as the motor driving this paper. The question I want to address here is whether it would be adequate to understand states of sensory awareness in the impure intentional way, that is, as involving reference to an intentional object and to an intentional mode or act. Impure intentionalists think so, as they apply the intentional mode-content-object structure also to experiences of pains, headaches, feelings, and sensations generally.

This paper argues that the impure intentionalist account of states of sensory awareness is phenomenologically implausible and provides an alternative to it that does not rely on intentionality. First, section 2 outlines impure intentionalism; section 3 how it applies to cases of pain and sensory awareness. In the fourth section, turning to Husserl, I show that as early as Logical Investigations (1900-1901) Husserl contested that sensation contents are intentional. While sensations can figure in higher level intentional acts, the 'essence' of sensations is not captured by such an intentionalist construal, on his view. I further show that Husserl maintained this account of sensory awareness as non-intentional states in Ideas $I$ and elaborated it in later works. On the basis of these late writings, the fifth part develops a reply to Crane focusing predominantly on so-called 'immanent association'. This, I argue, constitutes a form of nonintentional conscious activity, that is, without of itself involving reference to actprocesses or intentional objects. Instead, I suggest that sensory awareness can be understood functionally in non-intentional terms on the basis of association and the subjective affections that co-vary with its operations.

\section{Impure intentionalism}

On Crane's reading, intentionalism refers to the thesis that intentionality is the mark of the mental. In other words, it concerns the idea that, without exception, 'all mental states are 
intentional' (Crane 2009, 475). While Crane accepts this general idea, he denies that consciousness is determined solely by the intentional content, that is, by what is represented in or through any given conscious state. Instead, he favors a view coined 'impure intentionalism', which involves an intentional object, mode, and content. In order to understand Crane's motivation for impure intentionalism and its application to sensation contents, I first outline the details of this view as it applies to less controversial cases of mental states, such as thoughts, beliefs, wishes, and perceptions in this section.

By intentionality, Crane principally means the directedness of mental states upon intentional objects. A mental state, in other words, is always directed at or concerns an object. Crane operates with a very broad conception of 'intentional object'. The intentional object is said to be simply 'whatever it is on which your state of mind is directed' (Crane 2009, 476). For Crane, the idea that any state concerns or is directed at an intentional object is not supposed to mean more than that it is about something other than itself, whatever exactly that may be.

Crane is well aware of the problems that haunted Brentano's immanentist conception of objects. ${ }^{7}$ On Brentano's view, or at least the standard interpretation of it, the intentional object at which a state is directed belongs to that psychological state as an immanent component. ${ }^{8}$ Crane, on the other hand, takes himself to be following Husserl (and Husserl's critique of Brentano) in specifying the intentional object as transcendent to the act or state. For Crane, this transcendence of the state implies that the intentional object is 'never part of the state' (Crane 2009, 477). Put differently, it is 'never essential to an intentional object that it is the object of any particular state of mind' (p.476). The object's transcendence of the state thus simultaneously suggests its complete independence of mental states in general.

So far, the intentional object has been specified as 'whatever it is on which [the state] is directed' and as 'never part of the state'. This means nothing has yet been learned about what mental states themselves contain. On the impure intentionalist construal, the mental state itself consists of two fundamental components. To understand the first, we can take note that the same intentional object can be intended in various different ways. For instance, it can be desired, thought, hoped, felt, seen, and so forth. These different ways in which things are given Crane calls the 'intentional mode'. The intentional mode, then, does not concern the object the state is directed at - which transcends the state altogether - but the way in which the state is directed at the object.

To understand the second component of mental states, we can take note that we can relate to the same object in different ways even if the mode is held constant. For instance, I may believe that Tiberius succeeded Augustus or that he succeeded Octavianus. In both cases, the intentional object is the same (they are the same person), and so is the intentional mode (believing). The difference, on Crane's view, is one in 'intentional content' (Crane 2009, 477). It is a difference not in the way the object is intended, but 'in the way the intentional object is presented'.

This brief exposition should suffice to make clear the 'three dimensions' (Crane 2009, 480) of impure intentionalism: the mode, content, and object. It is worth highlighting here that although standard intentionalism indeed only refers to intentional content to explain consciousness, I think it would be unfair to sketch this position as if its proponents were

\footnotetext{
7 See Crane (2006).

${ }^{8}$ See Brentano $(1995,88)$ or Huemer (2014) for a discussion.
} 
simply oblivious to those dimensions Crane calls mode and object. Standard intentionalists do not 'overlook' (Crane 2009, 481) intentional modes; instead, they argue that the concept of mode is unnecessary. Contrary to impure intentionalism, they maintain that we can exploit differences in mode unproblematically in terms of differences in content. ${ }^{9}$ This claim is supported, among other things, by the idea that to see, wish, or think about an object is not merely a difference of a mode of intending; such differences are likewise reflected on the side of the intentional content. The acts of seeing and of thinking about a certain person, for instance, actually have very different representational contents; what we intend appears differently. In short, all talk of modes might be reducible to talk of contents - or so this argument goes.

For standard intentionalists, the term 'intentional content' is therefore best understood as broader than for impure intentionalists. Standard intentionalism is therefore a simpler theory, which should allow us to raise the question why anyone would want to opt for the impure intentionalist view at all. After all, the standard view purports to explain the same phenomena in a less complicated way. Ockham's razor leads to standard intentionalism.

To my understanding, Crane's impure intentionalism is in this respect justified through the fact that 'the task we are engaged in here is a phenomenological one' (Crane 2009, 488). ${ }^{10}$ Crane, then, seeks to provide a phenomenologically accurate description of consciousness. By contrast, standard intentionalists, as I see it, seek above all to naturalize consciousness. A standard intentionalist such as M. Tye (1995) reduces consciousness's phenomenological complexity to a single function of representing in order to make its naturalization comprehensible. Tye, in other words, is primarily concerned with providing a theory about a physical system's functional organization, and not first and foremost with one about phenomenological consciousness. This is why, for instance, Tye's hypothesis that pain represents damage to or disturbances within the system is not immediately refuted by the fact that people who are in pain do not experience pain as representing damage to any system. Impure intentionalism, on the other hand, seeks above all to excel in phenomenological accuracy. This shift in focus should justify its complexity relative to the standard view's exclusive reference to representational content - but also makes it more vulnerable to phenomenological criticism.

To conclude this section: we have seen that impure intentionalism is a phenomenological theory which suggests that all mental states involve a mode and content, and that they are always directed at an object. Moreover, this object is always independent of the state. Whereas this view seems to work well for many familiar conscious activities such as thinking, seeing, wishing, and so on, impure intentionalists also apply it to bodily pains, moods, headaches, sensory states, in short: to 'all mental phenomena' (Crane 2009, 474). In the following section, I first offer a critical outline of the impure intentionalist account of such states, after which I turn to Husserl to provide an alternative.

\footnotetext{
$\overline{9}$ See especially Lycan's (2015) treatment of Nickel's (2006) argument for non-conceptual content for a nice example of how standard intentionalists try to exploit the character of experience exclusively in terms of representational content.

${ }^{10}$ This point is repeated at several places: 'The line of thought developed earlier in this section is a defence of intentionalism as a phenomenological thesis' (Crane 2009, 487); 'Impure intentionalism gives a better description of this than pure intentionalism, since impure intentionalism can accommodate the way in which the 'seeming' itself can enter into the phenomenal character of the experience' (Crane 2009, 486).
} 


\section{Impure intentionalism and states of sensory awareness}

In this section, I want to zoom in specifically on the impure intentionalist construal of states of sensory awareness. As we have seen, impure intentionalism states that all mental states must be understood intentionally. This is no different with standard intentionalism. However, for impure intentionalists, intentionality consists of 'three dimensions': the mode and content, which belong to the state, and the intentional object, which is independent of it. Because intentionality thus construed is taken to exhaust the mental life in general, the impure intentionalist holds that 'fixing the intentional nature (mode and content) of the experience fix [es] its phenomenal character' (Crane 2009, 483). There is, in other words, nothing to the living-through of any experience that demands a description going beyond the tripartite division of content, mode, and object.

This account raises the question what kind of object - an object specified as transcendent to and independent of the state - states of sensory awareness would have. It is worth noting that this question need not be raised for standard intentionalism. There, intentionality is understood more or less plainly as representing. Where there is representing, there must be representational content. But there need not be an intentional object in play at which the state is phenomenologically directed. Impure intentionalists, however, think this view is altogether flawed, because it does not account for variations in mode and object.

Before proceeding to the impure intentionalist interpretation of states of sensory awareness, let me note that I $d o$ think there is something to say for certain variants of the standard intentionalist view that take such states to be intentional. This may seem surprising, given the significant phenomenological deficits of standard intentionalism Crane and others have pointed out. However, as I noted already, for standard intentionalists, to qualify the phenomenological character of sensory awareness as determined by representational content is usually meant as a theory about sub-personal states in a physical system. When Tye says that 'all states that are phenomenally conscious - all feelings and experiences - have intentional content' (Tye 1995, 93), he is not primarily trying to offer an accurate phenomenological description of mental states. Tye pursues a theory that conceivably translates phenomenological descriptions of conscious operations into the language of functional organization of natural science. While such a pursuit is certainly restrained in various ways by the phenomenology of experience, it is not a phenomenological theory, and hence it cannot be refuted simply for not adequately capturing all details of the phenomenology of intentionality.

Perhaps some may think I am too charitable to standard intentionalism here. At this point, I only want to note that standard intentionalism need not be discarded straightaway because of its phenomenological deficits, and that the arguments Crane raises against it seem insufficient to me. Given that standard intentionalism is a theory primarily about a system's functional organization and thus bears less substantially on phenomenology, I need have no quarrel with it here. Impure intentionalism, on the other hand, presents itself as a phenomenological theory, and that is why I am pursuing it here.

How, then, does impure intentionalism think about the objects of states of sensory awareness and bodily pains? For Crane, pain cannot be a matter of damage representation as some standard intentionalists have it, plainly because 'there is nothing in an experience of a headache which connotes damage to the subject' (Crane 2009, 488). The damage theory, in other words, is taken to be phenomenologically flawed. Of 
course, the theory of damage representation might work out at a sub-personal physiological level. This, however, as Crane rightly notes, would be to change the subject from consciousness to its underpinnings (for Crane, this is a reason to reject standard intentionalism - I already made clear why I think this is not the case).

On Crane's alternative, we should explain the 'phenomenal character of pain in terms of three things: intentional mode, intentional content and intentional object' (Crane 2009, 488). So what would be the object of pain sensations? As Crane puts it, the 'intentional object of a pain is the felt location of the pain, the part or region of the body which hurts' (Crane 2009, 489). This seems to suggest that, for instance, the pain sensations in a burned hand refer to the location of the hand as a body part, while a headache refers to the location of one's head. Since Crane takes location to transcend the state itself, it should live up to the criteria that have been set earlier for intentional objects.

Unfortunately, Crane does not say an awful lot more about the intentional objects of states of sensory awareness. Crane notes that he believes that the standard intentionalist's reference to damage representation is phenomenologically inaccurate. As it stands, however, it seems questionable whether the location thesis fares any better. Overall feelings of illness, fatigue, drowsiness, nausea, etc. do not seem to refer, phenomenologically speaking, to any particular location. To be sure, reference to a location might still hold water as a theory of the system's material-functional organization. But that amounts to admitting its phenomenologically flawed nature, and would put it on a par with standard intentionalism.

Apart from an intentional object, impure intentionalism needs to specify a mode and content for sensory states of awareness. To account for the intentional content, Crane refers us to the precise way in which the location as object is represented. Among other things, the specific quality of 'mineness' of sensory experiences - which seems to coincide to some extent with what Zahavi (1998a, b, 2005) has popularized as 'prereflective self-awareness' - is said to belong to the intentional content as well. For instance, as Crane puts it, 'if one feels that one has pain in one's arm, the arm is the intentional object of the experience, and its content is the representation of one's arm as one's own' (Crane 2009, 489).

To my understanding, taken as a phenomenological description of the distinctive quality of 'mineness' inherent to sensory awareness, this is a dubitable thesis. Much phenomenological work has been done on this topic, and I return to this briefly in the next sections. At this point, I only want to point out that the example Crane uses to specify the mode of pain experience unfairly changes the topic of discussion. If one 'feels that one has pain in one's arm', one executes a higher level intentional act; it involves turning one's attention to one's arm and turning it into an object of directedness. This, of course, lifts the genuine problem of the sensory state's phenomenal structure back to the level of ordinary intentional acts. The example therefore fails to address what (as I understand him) Crane takes himself to be after. Unfortunately, this leaves the impure intentionalist's interpretation of the contents of states of sensory awareness opaque.

Having specified object and content - the former as location, the latter as the specific way in which the location appears - the intentional mode needs to be addressed. For this, Crane points to that "which we generically call 'hurting" (Crane 2009, 489) as the intentional mode. Presumably, similar modes would exist for feeling, sensing, etc. To experience pain, then, is to be in a distinct mode of experiencing that can be put next to other modes such as believing, seeing, wishing, and sensing. Crane further explains that 
the 'distinct intensity and phenomenal character' of the felt pain should be understood as determinations of the intentional mode, that is, of the way in which the state is directed at its object, rather than as intentional content.

I will have more to say about the idea that pain experience - or any form of simple sensory awareness - should be understood as an intentional mode in the next section. At this point, I only want to express my doubts about the specification of pain intensity on the side of mode. At least on the impure intentionalist own account, a so-called act of hurting seems to be quite similar to an act of ordinary visual perception. Both have a content, mode, and an object. In the case of perception, however, it is common to exploit the fineness of grain of for instance the intensities of perceived colors on the side of the intentional content. Given their commonalities, it would appear consistent to exploit the intensity of pain similarly. Degrees of pain intensity then belong to the way of presentation of the hurting object (say, one's hurting arm), rather than to the mode of intending. If this is indeed a plausible alternative construal on the impure intentionalist's own terms, the decision to locate pain intensity on the side of mode seems arbitrary, if not far-fetched.

Although Crane's exposition is brief on this difficult issue, all three dimensions have now been addressed with regard to states of sensory awareness. Having listed some general objections already along the way, I now turn to Husserl for an altogether different take on the problem.

\section{Husserl on intentionality and non-intentional consciousness}

As we have seen, Crane's impure intentionalism differs from what I dubbed the standard intentionalist view. According to the standard view, generally construed, the phenomenal character of an experience - or what it is like to be in a particular state - is determined by its representational content. Crane's impure intentionalism, by contrast, specifies that 'three dimensions' are needed to describe the possible variations that occur in mental states: the mode, content, and object. We also saw that the complexity of this theory over against the standard view is in a way justified through the fact that 'the task we are engaged in here is a phenomenological one' (Crane 2009, 488). Impure intentionalism, in other words, does not reduce the phenomenological complexity of mental states to a single function for the sake of developing a unified theory that conceivably translates into natural language. Whatever benefits a reduction of modes to content might have, impure intentionalism claims sufficient grounds to resist it.

Given that impure intentionalism is thus justified by appeal to phenomenology, the question may now be raised what it adds to the classic phenomenological theories of intentionality such as Husserl's. Crane believes all variations of mental states are understandable in terms of the three dimensions of object, mode, and content. These distinctions, however, are not new; they can be found already in Logical Investigations. 11 Moreover, it is debatable whether this tripartite distinction alone suffices as a phenomenological description of mental states.

For instance, Crane's distinctions do not seem to clearly accommodate what Husserl specified as degrees of clarity of object intending. Degrees of clarity can be taken here to

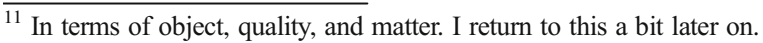


refer to seeing with watery eyes as much as to thinking with a foggy mind. It seems likely that, since degrees of clarity are no intentional modes (seeing and thinking are variations in mode, seeing watery or thinking foggily must be different variations), ${ }^{12}$ impure intentionalism would fit them under intentional content instead. Yet phenomenologically speaking degrees of clarity differ from changing perspectival intentions or non-conceptual fineness of grain, both of which also (presumably) belong to the intentional content on this construal. Importantly, degrees of clarity are not experienced on the side of what is intended in the way fineness of grain of represented color properties is (I do not see the object as being watery). In other words, they do not fit under intentional content either. I see no easy way for Crane's theory to offer a solution to this problem.

Furthermore, Husserl's theory of intentionality accounts for degrees of ego-attention involved in the intentional act, as well as for the doxic modalities of the object's presentation, meaning roughly the object's claim to being real or not. ${ }^{13}$ Also, Husserl accommodates the crucial workings of background understanding - which, although not represented in any ordinary sense, are essential to any act - in terms of so-called horizonal awareness. Phenomenological description seems to further compel us to account for the temporal structure of the unfolding of mental states, for the indispensable role of habits (habitus) ${ }^{14}$ in intentionality, and for the entwinement of intentional representation with the potentiality for bodily action. ${ }^{15}$ Last but not least, it seems necessary to address the important role sensation contents play as components of many types of mental states.

I touched upon some of these themes in my comparison of Husserl's theory of intentionality in Ideas $I$ to the standard intentionalist view in an earlier paper. In this paper, however, I only want to focus on the problem of sensation contents or sensory awareness. This means I ignore the other potential shortcomings of impure intentionalism relative to Husserl's theory that were just mentioned, in order to focus exclusively on the problem of sensation contents. The rest of this section first offers a general discussion of the development of Husserl's views on this topic, after which I flesh out a more concrete theory of sensory awareness in the final part.

Husserl's Logical Investigations contains the first presentation of his theory of intentionality. As stated at the opening of the fifth book, meaning and objectivity, central to all scientific activity, are essentially brought about in or through intentional acts of consciousness. Indeed, the fifth and sixth book together serve to develop a phenomenological theory of knowledge. This is no minute detail. Intentionality is central to Logical Investigations because it captures that part of consciousness relevant to a theory of knowledge, not because it covers the whole sphere of consciousness (as it does for Crane). Husserl, then, does not suggest intentionality exhausts the life of

\footnotetext{
$\overline{12}$ Crane actually seems to suggest at one point that blurry vision belongs to the intentional mode. If this is indeed the impure intentionalist view of degrees of clarity, it seems it obfuscates the obvious phenomenological difference between intentional mode or quality (seeing, thinking, etc.) and degrees of clarity.

13 The paradigmatic case here would be the imagined object, which has a different doxic modality than the perceived object, insofar as the former does not present itself as really existing.

${ }^{14}$ See especially Moran (2011) and Lohmar (2014).

15 As Husserl elaborates in later works, no intentional act ever stands in complete isolation of a practical horizon and one's potentiality to act upon what one is directed at. Perception in particular is said to involve a 'horizon of doing' (Husserl 2008, 363). As Husserl notes, 'perceiving is a doing' (Husserl 2008, 365); every 'I am directed at something' is simultaneously an 'I am doingly directed' (Husserl 2008, 366). Husserl, then, believed the adequate phenomenological description of perception must involve reference to the subjective horizon of possible bodily actions as a kind of background onto which individual acts of perception take place.
} 
consciousness. Instead, he notes that intentional experiences form an 'important class within the sphere of psychic experiences' (Husserl 1984, 353). ${ }^{16}$ Indeed, he deems it quite evident that 'no one would think of referring to the sensations themselves as [intentional] experiences' (Husserl 1983, 406).

The details of Husserl's account of intentionality in the fifth book and of the interplay of signitive and meaning acts in the sixth cannot be discussed here. ${ }^{17}$ Nevertheless, it is worth following the general outline of the fifth book briefly to see how it matches the impure intentionalist model. Here, Husserl identifies consciousness with all that is 'really' (reell) ${ }^{18}$ inherent in consciousness. That is to say, the intentional acts and their various essential components are taken to belong to the domain of consciousness and phenomenological inquiry. The act-structure contains, among others, the appearance of the object (Husserl 1984, 360-361). However, just as with the impure intentionalist view, the intentional object is considered to transcend consciousness (Husserl 1984, 358, 427). ${ }^{19}$ Whereas consciousness contains acts which are inherently outwardly directed, the object of directedness is not an inherent part of consciousness.

Second, Husserl continues to specify the different types of acts - as in judging, seeing, remembering, etc. - as the act's so-called 'quality'. Similar to Crane's concept of mode, the act-quality can be characterized generally as the way of intending something. So in perceiving or wishing for a cup of coffee on one's desk, different act-qualities establish the same object-relation in different ways.

Third, from the 16th section of the fifth book onwards, Husserl introduces a counterpart to the act-quality: the so-called matter. The matter and quality combined constitute the intentional essence: that which any intentional act necessarily has. As with Crane's concept of content, the matter on Husserl's account makes it possible to intend the same object with the same mode in different ways. For instance, the judgments 'Michael Jackson died age 50' and 'the King of Pop died age 50' have the same object-reference, yet they differ in a way not accounted for by the act's quality.

\footnotetext{
16 The concept of intentional experience is further terminologically equated with the concept of act. This means that when in Logical Investigations Husserl speaks of acts of consciousness, he speaks of intentionality, and vice versa (this also goes for his later works).

${ }^{17}$ See also Mohanty (1964) and Smith (1977) for their introductory overviews.

${ }^{18}$ Reell (here translated as 'really inherent') functions very differently from the English word 'real'. At no point is the empirically real structure of consciousness at stake in Husserl's phenomenology. Instead, real inherence denotes a certain way in which to speak of contents of consciousness, pointing to those contents that are 'immanent' in consciousness, i.e. those that are lived through, as opposed to the objects at which acts are directed.

${ }^{19}$ As mentioned, Crane believes he follows Husserl regarding the intentional object's transcending of the mental state. Crane insists that he 'must reject the thesis that intentional content determines intentional object' (Crane 2009, 477). For the impure intentionalist, the 'state is exhausted by its mode and content'; the object is 'never part of the state'. While Crane is right about Husserl's anti-immanentist theory of intentionality, he does not mention that Husserl claimed some kind of dependence of the object on consciousness which Crane does not accommodate. Husserl repeatedly emphasized that no object signifies a 'reaching out beyond the world which is for consciousness' (Husserl 1983, 121); that the 'true being of nature is not a second one next to mere intentional being' (Husserl 2002a, 276); that 'transcendental philosophy shows that the world is only thinkable as idea in the coherence of transcendental subjectivity' (Husserl 2002b, 26); that the 'transcendence [of the real object] is part of the intrinsic sense of anything worldly, despite the fact that [it] necessarily acquires all the sense determining it, along with its existential status, exclusively from my experiencing' (Husserl 1973a, 65 my italics). For Husserl, objects are given as consciousness independent, but the very sense of that independence is still an accomplishment referring back to consciousness. Husserl's view on the intentional object is thus actually very different from Crane's, although this is of no immediate concern in this paper.
} 
Different matters thus allow phenomenological differences in acts which share both object-relation and quality (Husserl 1984, 429-430, 497) - much indeed like the Fregean notion of sense.

This tripartite division roughly matches Crane's. Husserl, however, goes on to specify a fourth element, namely the sensation contents. Sensations are, Husserl maintains, 'totally different' (Husserl 1984, 396) from the object intended as well as the act's intentional directedness. First, sensations differ from the object insofar as the former are 'really inherent' in consciousness, whereas any intended object transcends the mental state. For instance, in hearing a song being played, I am intentionally directed at that song which transcends the intentional act. By contrast, I am not directed at the sound sensations out of

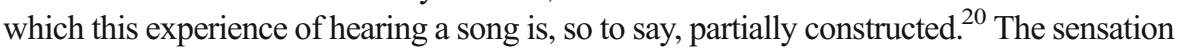
contents, then, are not transcendent to consciousness, but really inherent or immanent to the state. (This distinction coincides roughly with the one recently made by Byrne between sensory and sensible qualities, see (Byrne 2009, 272).)

Second, the sensations are also said to be totally different from the intentional acts proper. This is because the acts are essentially directed at something. The sensations, however, are not. At least potentially, sensations are 'building blocks of [intentional] acts'. Yet, as I quoted already, Husserl believes 'no one would think of referring to the sensations themselves as [intentional] experiences' (Husserl 1984, 406 italics added).

So far, Husserl's account distinguished the really inherent sensation contents, the also really inherent intentional acts (consisting of quality and matter), and the objects at which acts are directed, which are not really inherent parts of acts. We further saw that whereas the intentional acts are always directed at objects, the sensations are not, although they may function as building blocks for intentional acts.

This exposition already indicates two important differences with impure intentionalism. The first concerns the different explananda both theories address. Husserl's theory in Logical Investigations aims at providing some fundamental outlines of a phenomenological theory of knowledge. This is a very different task from a full investigation of conscious states in their own right. This, on Husserl's view, would necessitate many more distinctions than just quality, matter, object, and sensations some of which I listed earlier on. This complete phenomenological survey of consciousness is the theme of much of Husserl's mature transcendental work, where consciousness is repeatedly characterized as an endless field of possible a priori cognitions. The basic distinctions of Logical Investigations, however, do not lay claim to providing an exhaustive account of conscious states (as it does for Crane). There is in fact no good evidence that Husserl at any point considered that a viable suggestion.

The second difference was that Logical Investigations refers to sensation contents as non-intentional. To be sure, this should not withstand that sensations are, insofar as we are interested in 'consciousness in the pregnant sense' (Husserl 1983, 199), generally taken up into intentional acts. Sensations frequently figure as 'building blocks'; they constitute the basic 'stuff-stratum' which intentional acts animate in order to construe intentional contents. For themselves, however, sensations are not intentionally directed at anything. This point resurfaces in Ideas I, where Husserl remarks that 'we cannot say of each

\footnotetext{
${ }^{20}$ See also Lycan (2015) for more on the ambiguity of the term 'sensation' or 'phenomenal content' in contemporary debates.
} 
experience that it has intentionality' (Husserl 1983, 199), and that sensation (now called hyle) for itself has 'nothing pertaining to intentionality' (Husserl 1983, 203).

This raises the question how to characterize sensation contents, if not by reference to intentionality. In most of his earlier works up until Ideas I, Husserl refrained from providing concrete details about this difficult issue. This has led to the widespread view, popularized among others by R. Sokolowski (1964), that the early Husserl operated exclusively with a model of intentionality, where sensations function as unstructured data that await the 'animation' of intentional acts. On Sokolowski's suggestion, Husserl came to adjust this view only later, now claiming that sensations already stand under their own structuring laws even before they are intentionally animated.

There is, however, textual evidence indicating to the contrary that Husserl from early on rejected both the view that sensations are intentional and the view that they would be completely unstructured data of consciousness. I already pointed to important fragments from Logical Investigations and Ideas I which support rejection of the first thesis. Regarding the second, Husserl notes already in Thing and Space (1907) that sensations 'are not dispersed and without connection; they have a rigorous unity and a rigorous form' (Husserl 1997b, 57). Some years later in Ideas I, Husserl appears unwilling to characterize sensations either as outright intentional or as entirely unstructured, and deliberately leaves the question open. ${ }^{21}$ In short, then, there is some evidence that Husserl maintained throughout his career that sensations have to be accounted for in a different, non-intentional way.

To be clear, the suggestion that the phenomenological structure of sensations cannot be adequately accounted for in terms of an intentional mode-content-object structure does not rule out that sensations can be taken up into larger intentional structures. To say that sensory awareness is non-intentional is only to say that, taken for itself, it has its own phenomenological structure that is not analyzable in terms of modes, contents, and objects. ${ }^{22}$ Likewise, to say that sensations are non-intentional does not suggest that they are, for that reason, entirely unstructured - whether as mythical givens such as Sellars (1963) and McDowell (1996) criticized or as mysterious qualia criticized by Dennett (1988), Harman (1990), and others. (I return to qualia theory briefly at the end of this paper.)

In any case, Sokolowski got it right that Husserl's non-intentional account of states of sensory awareness was developed mostly in the 1920s and 1930s. In the next section, I turn to that later account for an alternative to the impure intentionalist reading. I focus specifically on one major non-intentional law Husserl identifies there, called immanent association. In doing so, I aim to provide an alternative to impure intentionalism about sensory awareness generally construed, thus abstracting from various types of sensory experiences. I further argue that while the intentional model is of no use in understanding sensory awareness and its distinctive affective quality or phenomenal content, we can instead take the latter to co-vary with the organizing processes of association.

\footnotetext{
${ }^{21}$ According to Ideas I, the issue of non-intentionally structured sensations is 'not to be decided here' (Husserl 1983, 204).

${ }^{22}$ What I thus call 'non-intentional' is not fundamentally different from what other scholars have called 'preintentional'. I prefer non-intentional here because it contrasts better with Crane's impure intentionalism. Other interpretations of Husserl that go beyond an exclusive concern with intentionality include Zahavi (1998a, 1998b 208-209), Costello (2012, 84-85), Bower and Gallagher (2013, 114), Pokropski (2015, 165), and Kozyreva (2016, 4-5), among others.
} 


\section{A non-intentional account of sensory awareness}

According to Husserl's later phenomenological account, prior to our taking interest in them, sensations are already pre-structured into more comprehensive 'fields of sensations' (Husserl 1997a, 72-79), or 'broad lived experiential fields' (Husserl 2001, 18). The concept 'field of sensations' is central to Husserl's work on sensory awareness, and we can take it as Husserl's way of addressing what in more contemporary idiom could be called 'states of sensory awareness' or 'sensation contents'. Fields of sensations, Husserl notes, form a 'more radical conception of passivity' (Husserl 1997a, 60) which is not brought about through intentional acts, but functions as a 'background that is prior to all [intentional] comportment and is instead presupposed by all comportment' (Husserl 2000, 291). Indeed, the suggestion that such fields are presupposed by intentionality implies that we cannot be properly aware of them. This is because if we direct our attention to them, an intentional act will animate them, and hence we will not be directed at them after all. ${ }^{23}$

The idea of fields of sensations thus requires accepting that there is something it is like for us to undergo certain experiences independently of our being intentionally conscious. ${ }^{24}$ This need not be as controversial an idea as it may seem at first. Simple examples of fields include the background noise of the humming computer while working, or the continuous pain sensations of a burned hand - in both cases prior to yielding any attention. Block (2003) illustrates a similar idea when he says that 'one might be involved in intense conversation while a jackhammer outside causes one to raise one's voice without even noticing or attending to the noise until someone comments on it - at which time one realizes one was aware of it all along' (Block 2003, 171-172). Husserl, likewise, explicitly notes that sounds can be experienced without necessarily being directed at them as objects: 'talk about a sounding tone [sometimes] denotes a state of sensation which [...] does indeed function as a stimulus but which does not possess the property of an object-consciousness, in which a sounding tone comes to consciousness as an object' (Husserl 2000, 25).

To be sure, one can also direct oneself toward the pain, the jackhammer, etc., and thereby execute intentional acts directed at objects. The act of 'feeling pain in this hand' is thoroughly intentional: it has a mode or quality (feeling), a content or matter (the specific way of the hand's presentation at this moment), and an object which it is about (hand or body part location). Yet, Husserl (like Block on this point) maintains, it is not like there was nothing at all before turning attention to the pain, the humming computer, or the jackhammer. Fields are structured before intentional awareness (in Crane's sense of a mode-content-object structure) enters stage. To the contrary, Husserl thinks one can make these things thematic only because something is already there which calls for our attention and motivates the execution of intentional acts.

On Husserl's later account, sensation data are subject to 'passive synthesis' - the non-intentional grouping together - which puts them into fields. This happens, first of all, through something called 'temporal synthesis'. Husserl famously held that

\footnotetext{
${ }^{23}$ This is not to say that they cannot be the target of phenomenological reflection. It only means that their phenomenological structure is such that they are principally not made thematic in intentional experiences, as fields of sensations are not objects in that sense.

${ }^{24}$ Moreover, Husserl insists that fields of sensations are silently doing their work all the time (Husserl 2001, 167).
} 
whatever enters into experience is, so to say, immediately glued together with the justpast. This gluing with the just-past is called retention. Husserl also maintains all experience involves empty future projections called protention. All experience thus stands in a flow; a purely isolated now-moment, phenomenologically speaking, does not exist. However, since temporal synthesis works equally on all states of consciousness, it says nothing specifically about states of sensory awareness. ${ }^{25}$ Temporal synthesis cannot provide a criterion for the selection of data; it cannot explain why certain data are grouped together into this background field and others into another. This is what the concept of 'immanent association' is supposed to address (Husserl 1997a, 74-75). That the organizing processes of association are immanent is to say that they - and the fields resulting from them - are not transcendent to the mental state. In other words, they are not objects of intentional awareness in the proper sense.

The association of the data of sensation into fields occurs on the basis of the way they resemble or differ from one another (Husserl 1997a, 72-76; 2001, 162-214). Differently put, the mechanism at stake is one of similarity and contrast. ${ }^{26}$ For instance, a stream of color impressions - as opposed to a stream of sound data or tactile sensations - can be passively associated into one field. This is because sound data differ from color and tactile data and thus are passively grouped into separate fields. Color impressions, in turn, also contrast from one another. A patch of red stands in contrast to a white background. Thus the red color data are associated into one field on the basis of being alike relative to the contrasting white background (Husserl 1997a, 72-76). As should be clear, this conscious activity of synthesizing data has little to do with, say, seeing a red mug on a white table. It must be understood as functionally distinct from intentional activity comporting to transcendent objects - which is what differentiates it from Crane's model.

Although Husserl does not say much about the matter, it seems plausible if not necessary to speak of a concurrent plurality of fields, e.g. of visual, auditory, tactile, olfactory fields etc., possibly with various subfields therein, as in pre-structuring the sound data of the humming computer into one field and the jackhammer in the background in another. The various sensory modalities of course differ in countless ways and so do the ways in which fields are experienced. But the general rule of the association of data through similarity and contrast should be everywhere the same.

For Husserl, the law of the association of sensations based on similarity and contrast is closely tied to what may be called their qualitative, felt or affective structure. Tactile sensations, pain sensations, or the jackhammer in the background are all immediately affective contents. In a sense, this concept of affection corresponds to what some philosophers today call phenomenal content. For Husserl, affections are the subjective feelings that accompany sensory stimulation and which motivate the agent to act. Affections always come in degrees of intensity. Husserl maintained that all fields harbor degrees of affections, which can grow stronger or weaker, to the extent that

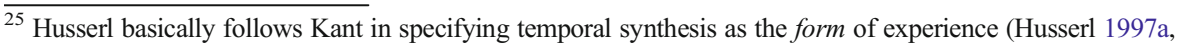
73; 2001, 173), which means it does not yet tell us anything about the contents of mental states. For introductions to Husserl's complex work on time-consciousness, see especially De Warren (2009), Kelly (2016), or Husserl (1966).

${ }^{26}$ I do not want to get into the question of what empirical factors determine similarity and contrast within any system's functional constitution in this paper. Instead, I here stick to the general concept of association as Husserl outlines it.
} 
they either force us to become attentive or become barely noticeable. If you don't readily understand what is meant by all this, slowly press a pen in your arm and increase and decrease pressure and you should experience all there is to it.

Husserl did not elaborate in detail on the functional relation between immanent association and affective quality. I do want to take things a bit further here and specify a functional relation between the processes of association and the affective quality of sensory experience. On the view I want to put forward, the affective quality of sensory experience can be understood as co-varying with the contrast established through immanent association. The subjectively felt intensity of sensory fields can be taken to stand in relative proportion to the sharpness of contrast established in immanent association. So for instance, the affective quality of a field of sounds or tactile sensations may sink away entirely if there is no relevant contrast established, i.e. if it fails to 'stand out' any longer in the organizing processes of association. On the other hand, the affection may also become so intense that it can no longer be ignored by the subject, if the associated contrast becomes too strong. The subjective affection thus correlates with the contrast established.

Let us take the sound of a jackhammer while working as a concrete example of how this works. At first, the sound data of the jackhammer are passively associated into one field, because they differ from other (e.g. visual and tactile) data. Let's say that the sounds do not yet affect you to the degree that you need to turn your attention toward that. Only if they did could an intentional act be executed and the transcendent object 'jackhammer' first appear to you. At this point, however, you do not experience an object called 'jackhammer'. You only experience an associated field harboring affections too weak to entice you to act upon it. But let's say that the jackhammer gets louder and louder, and as a result the field as a whole comes to stand in sharper contrast with your other experiences. As a result, the affective quality of the field will now likewise increase, possibly forcing you to pay attention to it.

The same goes for fields of other sensory modalities. Within any given field, it is possible that an affection grows so prominent that it grasps attention. At any point, a sharp contrast established in association can lead to an increased affective quality by which the field starts to stand out for the subject, thereby persuading the subject to intentionally turn toward it (Husserl 1997a, 76-79; 103-148). As Husserl puts it, strong affections emanating from the background may 'penetrate the ego', thereby 'awakening' it, thus motivating it to turn and see what is going on (Husserl 1997a, 76-79).

Clearly, this yields a very different picture of sensory experience and their affective contents than is sketched by impure intentionalists. There, sensory experience was understood intentionally. It involved a directedness toward a transcendent object. The affective quality then had to be located under the header of mode. By contrast, on the present account sensory awareness and their affective contents stand functionally independent from intentionality understood as a mode-content-object structure. Such a restriction of the scope of intentionality is not new in current literature. It is supported by so-called 'restricted intentionalists' (Kind 2007) such as McGinn (1997), Kind (2007), Dennett (2010), and many others. As McGinn writes, 'bodily sensations do not have an intentional object in the way perceptual experiences do' (McGinn 1997, 89). Kind, likewise, remarks that in cases of sensory awareness 'we cannot make sense of attending to the representational content of the experience' (Kind 2007, 424). Even Dennett notes that the 'heuristic value of giving an intentional interpretation' is limited 
(Dennett 2010, 89). On his view, there is "nothing to be gained by assigning [intentional] content to [for instance] the last-rank motor impulses that stimulate muscle contraction' (Dennett 2010, 89). It seems to me that this is true not only where a system's physiological organization is concerned; the phenomenology also supports it.

We saw that impure intentionalists believe that intentionality is the only relevant function of consciousness. Everything else - including the affective quality of sensory experience - can be tied into the intentional relation. The present picture objects to this. On my suggestion, the affective quality of sensory consciousness is not some kind of supervening surplus of the intentional structure. Rather than being parasitical upon intentionality, the association of fields and the affective content they produce are conditions of possibility for intentionality. Rather than being functionally superfluous properties of intentional acts, affections have a crucial, sui generis informative role to play, one which principally cannot be specified intentionally, because it comes altogether prior to that.

Many organic systems that we know to exist presumably have sensory experiences and are subjectively affected by them. Yet for many creatures, this does not necessarily result in the experience of a transcendent world in the proper sense or in intentional objects of any sort whatsoever. If we make sensory awareness and their accompanying affections a class of intentional acts, as impure intentionalists suggest, we block ourselves from all the right tools to understand those systems. The same goes for the phenomenology of our own sensory consciousness and other states escaping plain intentional description, as I have argued here. If we want to capture the phenomenology of those states without distorting it, we cannot fetishize intentionality. We need the nonintentional association of data into fields.

To close, let me mention that I think one may still rightly feel compelled by the impure intentionalist's reference to a quality of mineness in states of pain and sensory awareness. It is odd to speak of pain or sensory affection without it being someone's pain or affection. It seems that we cannot really think of affections or pains being manifest without someone in some sense experiencing them. If no one experiences pain, it simply is not there. A quality of mineness may therefore seem to be an essential component of states of sensory awareness after all, as impure intentionalists rightly specify.

My non-intentional reading thus faces the question whether we can understand the quality of mineness of sensory experience non-intentionally. Although this is a challenging issue, I think this can be done, and substantial phenomenological work has been done on pre-intentional self-awareness already. Time does not permit me to elaborate extensively on this here. I see no problem, however, in understanding a quality of mineness non-intentionally in terms of immanent association and affective qualities co-varying with that. On the present account, a non-intentional awareness of mineness can simply be taken as intrinsic to affections within associated fields. This is because, as we saw, there is no sense in speaking of affections without them being (in at least some minimal sense) someone's affections. Affections that are manifest in my body are mine plainly for the fact of being manifest at all. Insofar as I am thus affected, I have a minimal, non-intentional sense of mineness. We can thus conceivably bring the impure intentionalist reference to mineness back to the basic organizing processes of immanent association and the affections they give rise to in terms of contrast and likeness among data. 


\section{Conclusion}

I argued that we can understand states of sensory awareness non-intentionally. On my account, states of sensory awareness are a matter of association of sensations into fields. This process produces affective contents. Without extensively arguing for it, I suggested that the intensity of subjectively felt affections may be taken to co-vary with the contrast on the basis of which association organizes fields. To account for a quality of mineness in fields of sensations, it was argued that nothing substantial need be added to the basic function of association and the affections to which it gives rise.

To close, let me emphasize two points. First, my principal concern here was to develop an alternative to Crane's impure intentionalist model with respect to states of sensory awareness. In doing so, I have not denied the standard intentionalist's right to specify sensations in exclusively representational terms for whatever benefits they see in that. Instead, I only argued that the intentional model is phenomenologically inadequate at the sensory level, and that a functional, non-intentional alternative is available to describe such states.

Second, specifying sensation contents in non-intentional terms as I have done should not be taken to involve some kind of revival of qualia theory. Crane defines qualia theory as the view that 'there are non-intentional properties which contribute to phenomenal character' (Crane 2009, 482). On this definition, my account obviously is a form of qualia theory. But Crane's definition presupposes that there is no space between qualia and intentionality. The more commonly found notion of qualia - the one famously criticized by Dennett (1988), Harman (1990) and others - defines them as properties of mental states that are of a non-functional, non-informative type. A quale is 'raw material', 'atomic and unanalysable', a 'residual property' (Dennett 1988, 384-385) almost magical to anyone seriously attempting to understand consciousness functionally. But the image of sensory awareness I sketched does not match these descriptions. It also does not match what Block (2003) hypothesizes about 'mental paint' - whose reliance on thought experiments my proposal is far removed from. Instead, the present account can be taken to suggest that there are more functions to consciousness than intentionality and that, at least from a phenomenological viewpoint, it is necessary to create conceptual leeway between nonfunctional qualia and intentionality.

Open Access This article is distributed under the terms of the Creative Commons Attribution 4.0 International License (http://creativecommons.org/licenses/by/4.0/), which permits unrestricted use, distribution, and reproduction in any medium, provided you give appropriate credit to the original author(s) and the source, provide a link to the Creative Commons license, and indicate if changes were made.

\section{References}

Bain, D. (2003). Intentionalism and Pain. The Philosophical Quarterly, 53(213), 502-523.

Block, N. (2003). Mental Paint. In M. Hahn \& B. Ramberg (Eds.), Reflections and Replies: Essays on the Philosophy of Tyler Burge. Massachusetts: MIT Press.

Bourget, D. (2015). Representationalism, Perceptual Distortion and The Limits of Phenomenal Concepts. Canadian Journal of Philosophy, 45(1), 16-36.

Bower, M., \& Gallagher, S. (2013). Bodily affects as prenoetic elements in enactive perception. Phenomenology and Mind, 4(1), 108-131. 
Brentano, F. (1995). Psychology from an empirical standpoint. In O. Kraus (Ed.). (A. C. Rancurello, D. B. Terrell, L. L. McAlister, Trans.). London, New York: Routledge.

Byrne, A. (2001). Intentionalism defended. The Philosophical Review, 110(2), 199-240.

Byrne, A. (2009). Sensory qualities, sensible qualities, sensational qualities. In A. Beckermann, B. P. McLaughlin, \& S. Walter (Eds.), Oxford Handbook of Philosophy of Mind. Oxford: Oxford University Press.

Costello, P. R. (2012). Layers in Husserl's Phenomenology: On Meaning and Intersubjectivity. Toronto: University of Toronto Press.

Crane, T. (1992). The Nonconceptual Content of Experience. In In: The Contents of Experience. Cambridge: Cambridge University Press.

Crane, T. (1998). Intentionality as the Mark of the Mental. Royal Institute of Philosophy Supplement, 43, 229251.

Crane, T. (2003). The Intentional Structure of Consciousness. In A. Jokic \& Q. Smith (Eds.), Consciousness: New Philosophical Perspectives. Oxford: Oxford University Press.

Crane, T. (2006). Brentano's Concept of Intentional Inexistence. In M. Textor (Ed.), The Austrian Contribution to Analytic Philosophy. London: Routledge.

Crane, T. (2009). Intentionalism. In A. Beckermann \& B. McLaughlin (Eds.), Oxford Handbook to the Philosophy of Mind. Oxford: Oxford University Press.

De Warren, N. F. (2009). Husserl and the promise of time. Cambridge: Cambridge University Press.

Dennett, D. C. (1988). Quining Qualia. In A. Marcel \& E. Bisiach (Eds.), Consciousness in Modern Science. Oxford: Oxford University Press.

Dennett, D. C. (2010). Content and Consciousness. London: Routledge.

Dretske, F. (1995). Naturalizing the Mind. Cambridge: The MIT Press.

Harman, G. (1990). The intrinsic quality of experience. Philosophical Perspectives, 4, 31-52.

Huemer, W. (2014). Franz Brentano, The stanford encyclopedia of philosophy (Fall 2017 Edition). In E. N. Zalta (ed.). URL https://plato.stanford.edu/entries/brentano/. Access 26 June 2017.

Husserl, E. (1966). Zur Phänomenologie des Inneren Zeitbewusstseins (1893-1917). In R. Boehm (Ed.), Husserliana X. Den Haag: Martinus Nijhoff.

Husserl, E. (1973). Cartesianische Meditationen und Pariser Vorträge. Husserliana I. Den Haag: Martinus Nijhoff.

Husserl, E. (1983). Ideas pertaining to a pure phenomenology and to a phenomenological philosophy: first book: general introduction to a pure phenomenology. (F. Kersten, Trans.). Boston: The Hague, Lancaster: Martinus Nijhoff Publishers.

Husserl, E. (1984). Logische Untersuchungen. In U. Panzer (Ed.), Band I-II, Husserliana XIX/1-XIX/2. Den Haag: Martinus Nijhoff.

Husserl, E. (1997a). Experience and Judgment: Investigations in a Genealogy of Logic. Evanston: Northwestern University Press.

Husserl, E. (1997b). Thing and space: Lectures from 1907. (R. Rojcewicztrans, Trans). Dordrecht: Springer Science + Business Media, B.V.

Husserl, E. (2000). Ideas pertaining to a pure phenomenology and to a phenomenological philosophy: second book: studies in the phenomenology of constitution. (R. Rojcewicz, A. Schuwer, Trans.). Dordrecht, Boston, London: Kluwer Academic Publishers.

Husserl, E. (2001). Analyses concerning passive and active synthesis: lectures on transcendental logic. In R. Bernet (Ed.), Husserliana IX. (A. Steinbock, Trans.). Dordrecht, Boston, London: Kluwer Academic Publishers.

Husserl, E. (2002a). Einleitung in die Philosophie: Vorlesungen 1922/23. Husserliana XXXV, ed. by R. Bernet, U. Melle, Dordrecht: Springer Science + Business Media B.V.

Husserl, E. (2002b). Zur Phänomenologischen Reduktion: Texte aus dem Nachlass. Husserliana XXXVI, ed. by S. Luft, Dordrecht: Springer Science + Business Media, B.V.

Husserl, E. (2008). Die Lebenswelt: Auslegungen der Vorgegebenen Welt und Ihrer Konstitution. Texte aus dem Nachlass (1916-1937). Husserliana XXXIX, R. Sowa (ed.), Dordrecht: Springer.

Kelly, M. R. (2016). Phenomenology and the problem of time. London: Palgrave Macmillan

Kind, A. (2007). Restrictions on representationalism. Philosophical Studies, 134, 405-427.

Kozyreva, A. (2016). Non-representational approaches to the unconscious in the phenomenology of Husserl and Merleau-Ponty. Phenomenology and the Cognitive Sciences. https://doi.org/10.1007/s11097-016-9492-9.

Loar, B. (1988). Social Content and Psychological Content. In R. Grimm \& D. Merrill (Eds.), Contents of Thought. Tucson: University of Arizona Press.

Lohmar, D. (2014). Types and Habits: Habits and Their Cognitive Background in Hume and Husserl. Phenomenology and Mind, 6, 48-63.

Lycan, W. G. (2001). The case for phenomenal externalism. Philosophical Perspectives, 15, Metaphysics, 17-35. 
Lycan, W. G. 2015. Representational theories of consciousness. In Zalta EN (ed.). The Stanford Encyclopedia of Philosophy. URL = http://plato.stanford.edu/entries/consciousness-representational/.

Marcus, E. (2006). Intentionalism and the Imaginability of the Inverted Spectrum. The Philosophical Quarterly, 56(224), 321-339.

Martin, M. G. F. (2002). The Transparency of Experience. Mind \& Language, 17(4), 376-425.

McDowell, J. H. (1994). The Content of Perceptual Experience. The Philosophical Quarterly, 44(175), 190-205.

McDowell, J. H. (1996). Mind and World. Cambridge: Harvard University Press.

McDowell, J. H. (2013). The Myth of the Mind as Detached. In J. K. Schear (Ed.), Mind, Reason, and Beingin-the-World: the McDowell-Dreyfus Debate. London: Routledge.

McGinn, C. (1997). The Character of Mind. Oxford: Oxford University Press.

Mohanty, J. N. (1964). Edmund Husserl's Theory of Meaning. Den Haag: Martinus Nijhoff.

Moran, D. (2011). Edmund Husserl's Phenomenology of Habituality and Habitus. Journal of the British Society of Phenomenology, 42(1), 43-77.

Nickel, B. (2006). Against Intentionalism. Philosophical Studies, 136(3), 279-304.

Pace, W. (2007). Blurred Vision and the Transparency of Experience. Pacific Philosophical Quarterly, 88, 328-354.

Pokropski, M. (2015). Affection and Time: Towards a Phenomenology of Embodied Time-Consciousness. Studies in Logic, Grammar, and Rhetoric, 41(54), 161-172.

Schellenberg, S. (2011). Perceptual Content Defended. Noûs, 45(4), 714-750.

Sellars, W. (1963). Empiricism and the Philosophy of Mind. Harvard: Harvard University Press.

Shoemaker, S. (1998). Two Cheers for Representationalism. Philosophy and Phenomenological Research, $58(3), 671-678$.

Shoemaker, S. (2000). Phenomenal Character Revisited. Philosophy and Phenomenological Research, 60(2), 65-67.

Smith, Q. (1977). On Husserl's Theory of Consciousness in the Fifth Logical Investigation. Philosophy and Phenomenological Research, 37(4), 482-497.

Sokolowski, R. (1964). The formation of Husserl's concept of constitution. Den Haag: Martinus Nijhoff.

Stoljar, D. (2007). The Consequences of Intentionalism. Erkenntnis, 66(1), 247-270.

Tye, M. (1995). Ten Problems of Consciousness: A Representational Theory of the Phenomenal Mind. Cambridge: The MIT Press.

Tye, M. (2002). Representationalism and the Transparency of Experience. Nô̂s, 36, 137-151.

Van Mazijk, C. (2017a). Phenomenological approaches to non-conceptual content. Horizon: Studies in Phenomenology, 6(1), 58-78.

Van Mazijk, C. (2017b). Some reflections on Husserlian intentionality, intentionalism, and non-propositional contents. Canadian Journal of Philosophy, 47(4), 499-517.

Zahavi, D. (1998a). Brentano and Husserl on Self-Awareness. Études Phénomenologiques, 14(27/28), 127-168.

Zahavi, D. (1998b). Self-awareness and affection. In N. Depraz \& D. Zahavi (Eds.), Alterity and Facticity: New Perspectives on Husserl. Dordrecht: Kluwer Academic Publishers.

Zahavi, D. (2005). Subjectivity and Selfhood: Investigating the First-Person Perspective. Cambridge: MIT Press. 